\title{
Demography and Life Histories of Sympatric Patas Monkeys, Erythrocebus patas, and Vervets, Cercopithecus aethiops, in Laikipia, Kenya
}

\author{
Lynne A. Isbell • Truman P. Young • \\ Karin Enstam Jaffe • Anne A. Carlson • \\ Rebecca L. Chancellor
}

Received: 7 May 2008 / Accepted: 13 September 2008 /

Published online: 27 January 2009

(C) The Author(s) 2009. This article is published with open access at Springerlink.com

\begin{abstract}
Mortality patterns are thought to be strong selective forces on life history traits, with high adult mortality and low immature mortality favoring early and rapid reproduction. Patas monkeys (Erythrocebus patas) have the highest potential rates of population increase for their body size of any haplorhine primate because they reproduce both earlier and more often. We report here $10 \mathrm{yr}$ of comparative demographic data on a population of patas monkeys and a sympatric population of vervet monkeys (Cercopithecus aethiops), a closely related species differing in aspects of social system, ecology, and life history. The data reveal that 1) adult female patas monkeys have significantly higher mortality than adult female vervets; 2 ) infant mortality in patas monkeys is relatively low compared to the norm for mammals because it is not significantly different from that of adult female patas monkeys; and 3) infant mortality is significantly higher than adult female mortality in vervets. For both species, much of the mortality could be attributed to predation. An epidemic illness was also a major contributor to the mortality of adult female patas monkeys whereas chronic exposure to pathogens in a cold and damp microenvironment may have
\end{abstract}

\footnotetext{
L. A. Isbell $(\bowtie) \cdot$ K. E. Jaffe $\cdot$ R. L. Chancellor Department of Anthropology, University of California, Davis, CA 95616, USA e-mail: laisbell@ucdavis.edu
}

\section{T. P. Young}

Department of Plant Sciences, University of California, Davis, CA 95616, USA

K. E. Jaffe

Department of Anthropology, Sonoma State University, Rohnert Park, CA 94928, USA

\author{
A. A. Carlson \\ Department of Zoology, University of Wisconsin, Madison, WI 53706, USA
}

A. A. Carlson

Defenders of Wildlife, 109 S. 8th St., Bozeman, MT 59715, USA 
contributed to the mortality of infant vervets. Both populations experienced large fluctuations during the study period. Our results support the prediction from demographic models of life history evolution that high adult mortality relative to immature mortality selects for early maturation.

Keywords demographic models $\cdot$ fecundity $\cdot$ mortality $\cdot$ primates $\cdot$ life history evolution

\section{Introduction}

In a world with tremendous year-to-year variation in the biotic and abiotic environments of organisms, it is clear that long-term data sets are needed if we are to understand fully the ecology and evolution of organisms, including life history evolution. Researchers have long recognized that lifespan correlates with other life history traits, i.e., long-lived animals tend to have a larger body size, reproduce at a later age, and have fewer offspring than short-lived animals. Early formulations of life history theory placed these traits along a qualitative continuum of r-selected and K-selected (MacArthur and Wilson 1967; Pianka 1970). Long-lived animals were Kselected because they lived in stable environments, putting a premium on intraspecific competition for food and favoring traits that assist in competition, such as late reproduction and high per-offspring investment. At the other end of the continuum, short-lived animals were r-selected because they lived in variable environments that periodically eliminated large numbers of individuals. Their populations therefore often grew exponentially during recovery from population crashes, and this put a premium on early and rapid reproduction (MacArthur and Wilson 1967; Pianka 1970). As early as the 1970s, this approach was criticized for its lack of mathematical rigor and conflation of multiple selective and selected variables (Bielby et al. 2007; Stearns 1992; cf. Reznick et al. 2002).

These early $\mathrm{r}$ - and $\mathrm{K}$-selection models were later replaced by more rigorous mathematical models of life history evolution (Charnov 1993; Stearns 1992). The newer models of life history evolution have moved away from relative environmental stability as the direct causative factor for differences in life history to focus on differential mortality of age classes. Potential causes of such differential mortality include any environmental factor that can differentially affect the vulnerability of an age class over another, e.g., predation, resource competition, and disease (Reznick et al. 2002). Some of the models, like r- and K-selection theory, emphasized variability in adult and juvenile survivorship rates (Orzack and Tuljapurkar 1989, 2001; Tuljapurkar 1982, 1990). Other models examined mean survivorship rates (Charnov 1993; Charnov and Shaffer 1973; Cole 1954; Young 1981). Both classes of models either indirectly or directly emphasize the relative survivorship of adults vs. juveniles (Dewar and Richard 2007; Richard et al. 2002). Under these demographic models of life history evolution, animals that have low adult mortality relative to juvenile survivorship evolve late maturation and low reproductive output, because adults have greater reproductive value than juveniles. In contrast, shorterlived animals that have high adult mortality relative to juveniles often evolve early maturation and high reproductive output, because there is a greater chance that the 
adults will not live very long. In practice, variation in adult survivorship seems to have a greater influence on life history evolution than variation in juvenile survivorship (Reznick and Bryant 2007; Reznick et al. 2001; Young 1981, 1990).

In vertebrates in general, mortality of immatures normally greatly exceeds adult mortality (Charnov 1993). Primates are typical vertebrates in this respect (Dobson and Lyles 1989). However, both adult and immature mortality tend to be lower in primates than in other mammals of similar body size (Charnov 1993). As an order, primates also tend to live longer than most other mammalian orders (Austad and Fischer 1992). There is also variation within primates. For instance, there is a strong negative correlation between body size and maximum potential population growth rate (Harvey and Clutton-Brock 1985; Ross 1988). Smaller-bodied primates reproduce earlier and more frequently, and sometimes even have larger litter sizes, e.g., twinning in Callitrichidae. This is consistent with similar correlations within other mammalian taxa (Harvey et al. 1989), although primates have distinctly lower intercepts (Charnov 1993).

There can be strong phylogenetic signals in the data sets, in part because closely related animals tend to have similar body size as well as similar ecological profiles. Thus, any comparison of life history traits would ideally control for phylogeny in addition to body size. Patas monkeys (Erythrocebus patas) and vervets (Cercopithecus aethiops) are 2 primates that are closely related and that often live sympatrically. Indeed, molecular evidence suggests that patas monkeys and vervets are more closely related to each other than they are to other primates (Tosi et al. 2003, 2004, 2005). However, they differ in social system and ecology, and so can provide a phylogenetically controlled comparison for examining the demographic model of life history evolution. In both species females are philopatric, i.e., they live in their natal groups and home ranges for life. Where they are sympatric, the 2 species also share the same mating and birth seasons. However, groups of patas monkeys include only 1 resident male year-round, live at very low densities, feed primarily on arthropods and gum, travel long distances each day in very large home ranges, and live away from rivers (Isbell in press). In contrast, vervet groups typically include multiple males yearround, live at higher densities, feed more on flowers and gum, travel shorter distances in smaller home ranges, and forage and sleep near rivers and other waterways (Isbell and Jaffe in press). Although patas monkeys and vervets may live in the same ecosystem and face the same predators (Isbell and Enstam 2002), their differential use of the environment may subject them to different selective pressures and mortality patterns.

Patas monkeys and vervets also differ in their life histories. Female patas monkeys have extremely high reproductive rates, with most reproducing in their third year and reproducing every year thereafter (Chism et al. 1984; Nakagawa et al. 2003; this study). Female vervets, in contrast, typically reproduce for the first time at 4-6 yr and, although it is possible for vervets to reproduce every year, individuals in habitats with less food and water tend to reproduce at a slower rate (Cheney et al. 1988). We reexamined published fecundity schedules across primate species (Ross 1992) by plotting the residuals of the regression of body size vs. maximum potential population growth rate against body size. After thus controlling for the effects of body size, the analysis revealed that patas monkeys have the greatest maximum potential population growth rate, for their body size, of any haplorhine primate 


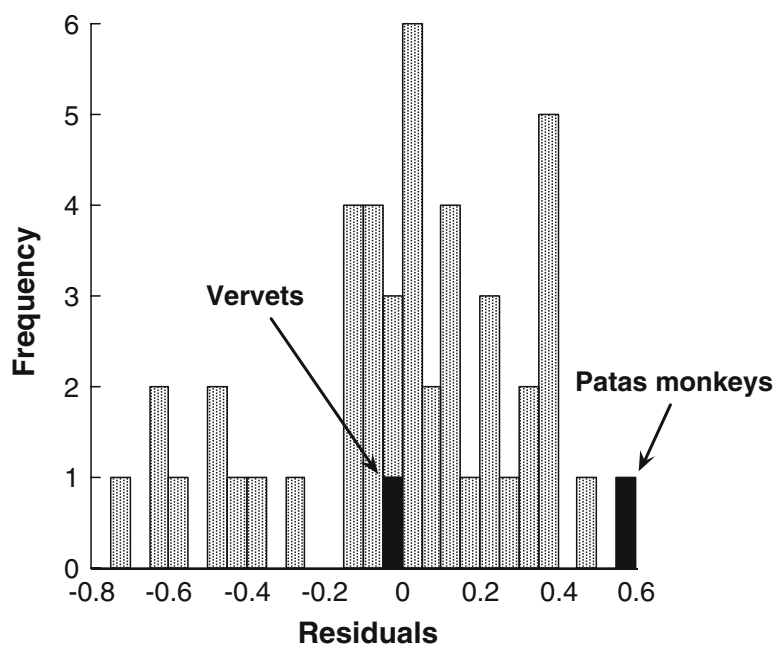

Fig. 1 Histogram of the residuals for the linear regression between body mass and maximum potential rate of increase, both log-transformed (data from Ross 1992). The 2 black data points are for vervets (middle) and patas monkeys (far right), indicating that vervets lie precisely in the regression line, but patas monkeys have the greatest maximum potential population growth rate for their body size of any haplorhine primate.

(Fig. 1). This does not mean that their real-world populations are always increasing, but instead that, if they experienced no mortality, their populations have the intrinsic ability to increase rapidly. In nature, high maximum potential growth rates are typically offset by high mortality rates.

Why do patas monkeys and vervets differ in their life histories, and in particular, why do patas monkeys have such high maximum potential rates of population increase? The demographic hypothesis predicts that this life history difference would be favored if, relative to vervets, patas monkeys have high adult female mortality and relatively low immature mortality, even if both had stable population sizes. Here we present demographic data from a comparative 10-yr study of patas monkeys and vervets that allow us to answer these questions and test the prediction of the demographic theory of life history evolution.

\section{Methods}

Study Site and Subjects

We studied 1 group of patas monkeys and 2 groups of vervets at Segera Ranch $\left(36^{\circ} 50^{\prime} \mathrm{E}, 0^{\circ} 15^{\prime} \mathrm{N}\right.$, elevation $\left.1800 \mathrm{~m}\right)$ in the Laikipia District of Kenya, year-round from August 1992 to March 2002, followed by irregular censuses from April 2002 to July 2002. The climate is semiarid with weakly trimodal rainfall and a distinct dry period from December to March, but with extensive year-to-year variation in both total rainfall and the pattern of rainfall. Over $10 \mathrm{yr}$, we collected daily rainfall 
records at 4 different sites, 1 site at a time, all $\leq 20 \mathrm{~km}$ of the monkeys' home ranges.

The vegetation is primarily Acacia drepanolobium bushed grassland (Young et al. 1997, 1998), with ribbons of Acacia xanthophloea woodland along wet drainages. Patas monkeys at our site spend all of their time in the Acacia drepanolobium bushed grassland, whereas vervets spend $c a$. $70 \%$ of the daytime in this habitat (Pruetz and Isbell 2000). Patas monkeys did not use the Acacia xanthophloea woodland, but vervets often fed and always slept in this habitat (Isbell et al. 1998). Thus, although there is overlap in habitat type, patas monkeys live their lives and spend their nights in situations that may make them more vulnerable to predators (Enstam and Isbell 2002, 2004). Confirmed or strongly implicated predators of monkeys at the study site include leopards (Panthera pardus), black-backed jackals (Canis mesomelas), and martial eagles (Polemaetus bellicosus; Isbell and Enstam 2002). Cheetahs (Acinonyx jubatus), lions (Panthera leo), and wild dogs (Lycaon pictus) are also potential predators.

We easily identified adult vervet individuals by natural markings. We identified all vervets in both groups as individuals by 1994 after we marked the immatures once with Nyanzol D hair dye. The hair dye enabled us to clarify and confirm identities that we had discerned with scars, broken bones, and natural markings, e.g., coat coloration, shape of the tail tip, and facial shape and coloration. After that, complete group censuses were possible every observation day. We also marked adult female patas monkeys once with hair dye to clarify and confirm identities of individuals. From 1992 to 1998, we did not mark infant patas monkeys but identified them by association with their mothers until the next birth season, after which we no longer identified them until they became adults. Before 1999, complete group counts were opportunistic. In 1999, we began dyeing immature patas monkeys, and remarked them $c a$. every 3 mo. After we dyed the immatures, complete group counts were possible every observation day. We analyzed only complete group counts.

We focus on adult females, and individuals in their first year of life, classified here as infants. Because we did not always recognize juveniles as individuals, we do not have as reliable data on them, and we include them only in the discussion of differences in mortality rates between age classes. We easily distinguished age classes by body size because both species reproduce seasonally, with $\geq 1$ yr of separation between each birth cohort. At the beginning of the study, we classified females of both species as adults if they had elongated nipples. We considered female vervets born during the study adults at age 4, even if they had not yet reproduced, because females of that age can reproduce elsewhere (Cheney et al. 1988). Because we did not mark most (30 of 37) female patas monkeys born during the study and surviving to reproduce were not marked as infants, we did not recognize them as individuals until they gave birth, and classified them as adults at that time. We also used facial coloration to determine age. As female patas monkeys mature, their noses become progressively whiter until age 3, when their noses are completely white. Unlike the western subspecies, Erythrocebus patas patas (Loy, 1974), East African female patas monkeys (E. p. pyrrhonotus) do not show changes in nose coloration with reproductive status; the noses remain white once females reach adulthood (Isbell in press). All primiparous females were larger than nonadults and had completely 
white noses. Only 1 female had an entirely white nose in the year before she gave birth for the first time; she was likely to have been $4 \mathrm{yr}$ old when she first reproduced.

In most cases we knew birth dates to within several days. In many cases, we also knew death and disappearance dates for immature vervets, infant patas, and adult females of both species to within several days. We did not always precisely know death and disappearance dates for juvenile patas monkeys in the years before we identified them individually because as juveniles mature, they reduce proximity to their mothers. We used group censuses to confirm the number of juveniles alive during those years and to estimate yearly juvenile mortality rates. Juvenile mortality rates of patas monkeys are likely to be overestimates because we could rarely distinguish between juvenile males and females, and some males may not have died but simply dispersed. We calculated yearly death and disappearance rates for infants, juveniles, and adult females of both species in January of the following year.

We largely followed Isbell (1990) to classify the probable cause of death for infants and adult females. We classified deaths of individuals whose damaged remains we found as confirmed predation. When we observed the group $\leq 72 \mathrm{~h}$ after the disappearance of an apparently healthy individual in that group, we classified the disappearance as suspected predation. When disappearances involved both the mother and infant, we also classified their disappearances as suspected predation (Isbell (1990) did not include this category). We classified animals that showed visible signs of ill health or injury before their disappearance death by illness. We restricted dying after being orphaned and suspected infanticide to infants. We suspected infanticide when we found an infant with bite wounds dead after it was attacked by an adult male monkey. When an individual disappeared while the observer was absent from the group for $>3 \mathrm{~d}$, we could not easily assign the probable cause of mortality and classified it as unknown.

\section{Statistical Analysis}

For all statistical analyses, we conducted Mann-Whitney $U$ tests via VassarStats (http://faculty.vassar.edu/lowry/VassarStats.html). For tests involving yearly mortality rates, we used census information in addition to individual histories. For other comparisons involving life histories, we used only individuals for which we had reliable demographic histories, i.e., known birth and death dates. Because there were many more unexplained deaths among infant vervets than among infant patas monkeys, we also compared rainfall in the birth month for infant vervets whose disappearances we could not attribute to predation or being orphaned, i.e., those classified as dying of unknown causes, against rainfall in the birth month for infants that survived their first year. We conducted this analysis because cold or damp environmental conditions are frequently associated with higher infant mortality in humans, the primate species for which the causes of infant mortality are best known. For most infants, the birth month was obvious. However, in some cases, there were 2 possible birth months, e.g., we might have first seen an infant born toward the end of the month at the beginning of the next month. In such cases, we calculated the birth month's rainfall as the average of the 2-mo rainfall. All tests were 2-tailed, with statistical significance set at $p=0.05$. 


\section{Results}

\section{Environmental Variability}

The mean annual rainfall was $720 \mathrm{~mm}$. We witnessed a tremendous range of monthly and yearly rainfall, including one of the wettest years (the El Niño year of 1997, continuing into February, 1998) and one of the driest years (2000) on record for Laikipia. Rainfall in 1997 was 172\% and, in 1998, 127\% of the mean annual rainfall, whereas rainfall in 2000 was $55 \%$ of the mean annual rainfall (Fig. 2a, b).
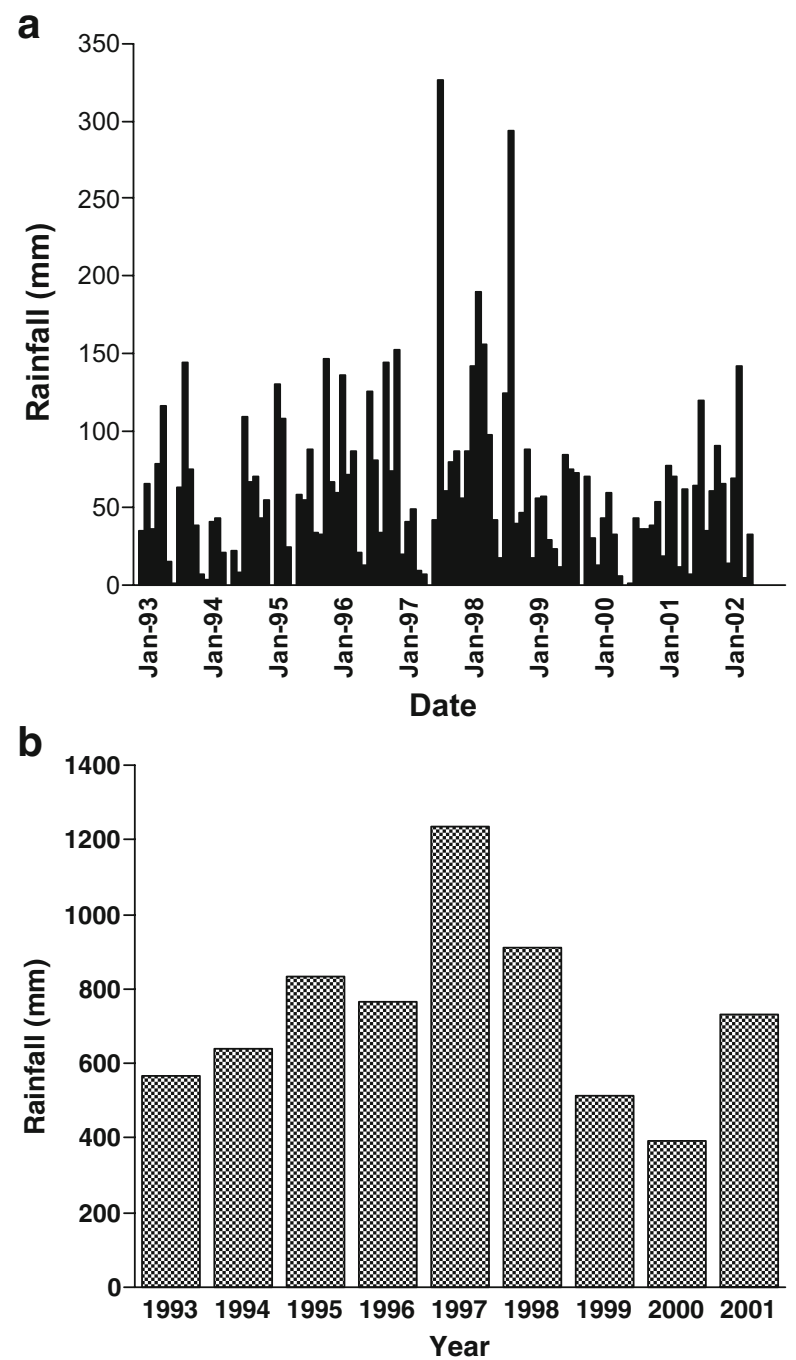

Fig. 2 (a) Monthly rainfall over $10 \mathrm{yr}$. Each bar represents 1 mo of total rainfall. Note the extensive variability over time. (b) Total yearly rainfall over 9 complete yr. 
Population Dynamics and Fecundity

Group sizes changed dramatically (Fig. 3). From 1992 to 1997, the patas monkey group nearly doubled in size, while the 2 vervet groups remained essentially stable (in this figure, the numbers of the 2 vervet groups are combined). From 1998 to 1999 , both patas and vervet populations declined greatly in size but for different reasons. The 2 vervet groups fused in July, 1999. After the declines, both species' population numbers remained stable for a time, but numbers of patas monkeys declined again in 2001. When the patas group declined to 7 in August 2001, it was temporarily overrun by a group of $c a$. 20. That group came into the study group's core area, intermingled apparently peacefully with the study group for $c a$. $1 \mathrm{wk}$, and then left. This was unusual because female patas monkeys are normally aggressive toward other groups and we had seen no group in the entire home range of the focal group during the previous $5 \mathrm{yr}$. It may be relevant that the focal group had lost its resident adult male 1 mo before the incursion. Males are aggressive to all other males, including males that are resident in female groups. A male that is resident in a female group often scans the environment from a tall tree for a long time before abruptly leaving the tree and running far away from his group. It is possible that he is responding to a male in another group and that his actions prevent an intergroup encounter involving females by keeping the male, along with the rest of his group, at a much farther distance than they would otherwise approach.

Our findings on fecundity are consistent with those of other studies of vervets and patas monkeys (Cheney et al. 1988; Chism et al. 1984; Nakagawa et al. 2003) and confirm Ross's (1992) analysis. Mean age at first reproduction of the 3 female vervets born during our study and surviving to reproduce (out of 19 infants unambiguously sexed as females) was $5.1 \mathrm{yr} \pm 0.8 \mathrm{SE}$. The small sample size

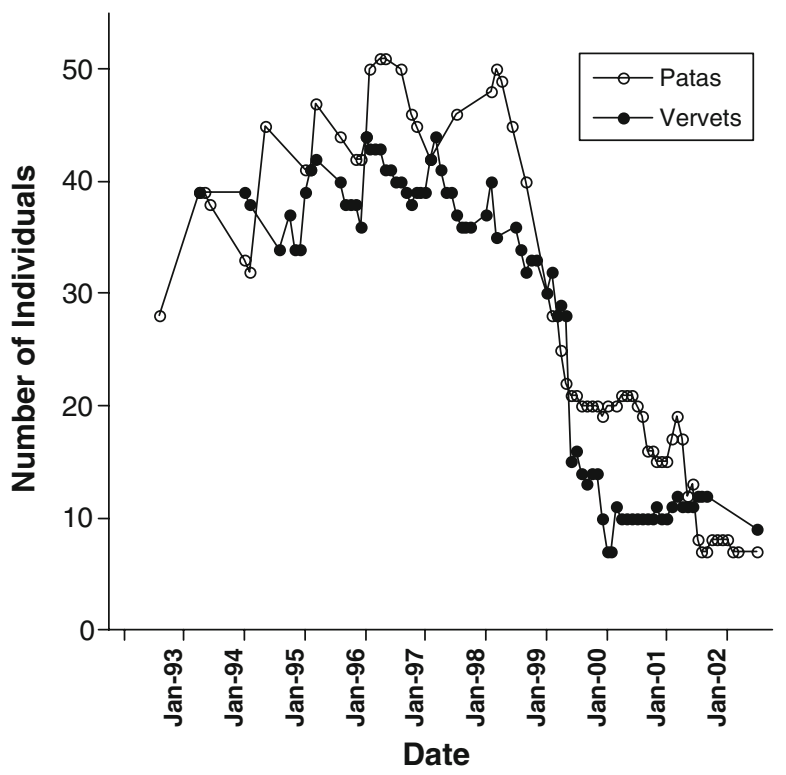

Fig. 3 Population size of patas monkeys (1 group) and vervets ( 2 groups) over time. 
emphasizes the high mortality of immature vervets. The mean age at first reproduction is greater than that of a larger sample of female vervets in Amboseli National Park, Kenya, living in highly productive habitats (mean=4.4 yr) and similar to that of female vervets in Amboseli's poorer habitats (mean $=5.4 \mathrm{yr}$; Cheney et al. 1988). The mean age at first reproduction would have been greater had it not been for 1 female that, at $3.5 \mathrm{yr}$, extraordinarily gave birth during the normal mating season after the El Niño rains of 1997. (A multiparous female also gave birth during the mating season that year.) The 2 other adult females reproduced for the first time at 5.8 and $6.1 \mathrm{yr}, \mathrm{ca} .6$ mo later than groups in poor habitats in Amboseli. Rainfall is a major determinant of plant productivity in tropical regions (McNaughton 1985), and both the earlier age at first reproduction for the single maturing female and the difference in timing of reproduction after heavy rains reveals that vervet life history events are highly responsive to ephemeral changes in environmental conditions.

Of the female patas monkeys born during the study and maturing to adulthood, age at first reproduction was $3 \mathrm{yr}(n=24)$, which is consistent with other studies of patas monkeys in Kenya and Cameroon (Chism et al. 1984; Nakagawa et al. 2003). Unlike vervets, patas monkeys showed no positive response to heavy rainfall, and it is likely that they are already at the upper limit of their reproductive output.

The number of offspring per female per year averaged $0.62( \pm 0.11)$ in vervets $(n=$ 10 years) and $0.79( \pm 0.07)$ in patas monkeys ( $n=9$ years), i.e., $62 \%$ of all adult female vervets and $79 \%$ of all adult female patas monkeys reproduced each year. During the entire study, vervets produced 58 infants, and patas monkeys produced 85 infants. In the first several years of the study when the vervet population was stable and the patas monkey population was increasing, adult female vervets had an average of 0.84 offspring per year (1993-1997) and adult female patas monkeys had 0.92 offspring per year (1994-1998; Table I). Mean interbirth interval for vervets was 13.3 mo $( \pm 0.6$, $n=31)$ and for patas monkeys, 12.9 mo $( \pm 0.8, n=29)$. In Amboseli, the mean interbirth interval for vervets ranged from 13.8 to 21.3 mo for 3 groups, with the longest interbirth intervals in poorer habitat (Cheney et al. 1988). The interbirth interval for patas monkeys at our study site is intermediate between that of another population of patas monkeys studied in Laikipia in the 1980s (11.8 mo), and Erythrocebus patas patas in Cameroon (14.4 mo) (Chism et al. 1984; Nakagawa et al. 2003).

\section{Mortality of Infant and Adult Female Vervets}

The mean annual mortality rate of infant vervets was $48.3 \%( \pm 10.0$, range $=14$ $100 \%, n=10$ yr; Fig. 4). Of 58 infant vervets, 28 (48\%) died before they reached 1 yr. Excluding 1999, a year of extraordinary predation in which infant mortality was $100 \%$, mean annual infant vervet mortality was $40.9 \%$. In contrast, the mean annual mortality rate of adult female vervets for all years was $14.7 \%( \pm 4.0$, range $=0-45 \%$, $n=11 \mathrm{yr}$ ). Excluding 1999, a year of extraordinary predation in which adult female vervet mortality was $45 \%$, mean annual adult female mortality was $11.6 \%$. For the $6 \mathrm{yr}$ from 1992 to 1998, when the vervet population was stable, a mean of 0.8 adult female vervets died per year (range $=0-2$, median $=1$ ). Throughout the study, a mean of 2.8 infant vervets $(n=10 \mathrm{yr})$ and 1.3 adult female vervets $(n=11 \mathrm{yr})$ died each year. In only 3 yr $(27.2 \%)$ did $>1$ adult female vervet die (Table I). High infant 
Table I Annual birth and death rates in patas monkeys and vervets

\begin{tabular}{|c|c|c|c|c|c|c|c|}
\hline \multirow[t]{2}{*}{ Year } & \multicolumn{3}{|l|}{ Infants } & \multicolumn{4}{|l|}{ Adult females } \\
\hline & No. born & No. died & $\begin{array}{l}\text { Mortality } \\
\text { rate }\end{array}$ & $\begin{array}{l}\text { No. of adult } \\
\text { females }\end{array}$ & $\begin{array}{l}\text { Births/ } \\
\text { female }\end{array}$ & No. died & $\begin{array}{l}\text { Mortality } \\
\text { rate }\end{array}$ \\
\hline \multicolumn{8}{|c|}{ Patas monkeys } \\
\hline 1992 & & & & $\geq 7$ & & & \\
\hline 1993 & & & & 11 & & 0 & 0.00 \\
\hline 1994 & 13 & 1 & 0.08 & 14 & 0.93 & 3 & 0.21 \\
\hline 1995 & 13 & 3 & 0.23 & 13 & 1.00 & 3 & 0.23 \\
\hline 1996 & 9 & 1 & 0.11 & 10 & 0.90 & 3 & 0.30 \\
\hline 1997 & 15 & 2 & 0.13 & 16 & 0.94 & 3 & 0.19 \\
\hline 1998 & 14 & 3 & 0.21 & 17 & 0.82 & 8 & 0.47 \\
\hline 1999 & 3 & 2 & 0.67 & 11 & 0.27 & 5 & 0.45 \\
\hline 2000 & 8 & 5 & 0.63 & 10 & 0.80 & 4 & 0.40 \\
\hline 2001 & 8 & 5 & 0.63 & 10 & 0.80 & 7 & 0.70 \\
\hline 2002 & 2 & 0 & 0.00 & 3 & 0.67 & 1 & 0.33 \\
\hline \multicolumn{8}{|l|}{ Vervets } \\
\hline 1992 & & & & 10 & & 0 & 0.00 \\
\hline 1993 & 7 & 1 & 0.14 & 10 & 0.70 & 0 & 0.00 \\
\hline 1994 & 9 & 5 & 0.56 & 11 & 0.82 & 1 & 0.09 \\
\hline 1995 & 10 & 4 & 0.40 & 11 & 0.91 & 1 & 0.09 \\
\hline 1996 & 8 & 2 & 0.25 & 9 & 0.89 & 2 & 0.22 \\
\hline 1997 & 8 & 6 & 0.75 & 9 & 0.89 & 1 & 0.11 \\
\hline 1998 & 7 & 3 & 0.43 & 10 & 0.70 & 2 & 0.20 \\
\hline 1999 & 6 & 6 & 1.00 & $11^{\mathrm{a}}$ & 0.55 & 5 & 0.50 \\
\hline 2000 & 0 & 0 & & 5 & 0.00 & 1 & 0.20 \\
\hline 2001 & 3 & 1 & 0.33 & 4 & 0.75 & 0 & 0.00 \\
\hline 2002 & 0 & 0 & & 4 & 0.00 & 1 & 0.25 \\
\hline
\end{tabular}

The populational data are from 2 groups of vervets and 1 group of patas monkeys.

${ }^{a}$ Data from 1 adult female vervet that transferred to a nonfocal group in December 1999 are not included in the table after 1999.

mortality and low adult mortality of vervets is typical of mammals in general (Caughley 1966, 1977; Richard 1985, p. 283), including humans without access to antibiotics (Weeks 1996, p. 186).

Of the 10 adult female vervets that were parous in 1993, and so were $\geq 4$ yr of age, the average age at death was $\geq 9.3( \pm 0.8)$ yr; all of them died before the study ended. The oldest adult female vervet lived to be $\geq 12$ yr. Only 3 female vervets born during the study survived long enough to become adult and reproduce. One died at $5.5 \mathrm{yr} ; 2$ were still alive and $7 \mathrm{yr}$ old by the end of the study. In addition to the 2 surviving adult females, 2 other nulliparous females, age 4 and 5, remained alive at the end of the study. Thus, of the 19 female vervets that were either adults at the beginning of the study or became adults later, 15 (79\%) had died by the end of the study.

\section{Mortality of Infant and Adult Female Patas Monkeys}

Differences in mortality between infant and adult female patas monkeys were striking for the unusual pattern of low infant mortality relative to adult female mortality. Of 85 infants born over 9 yr, 22 (26\%) did not survive their first year. The 


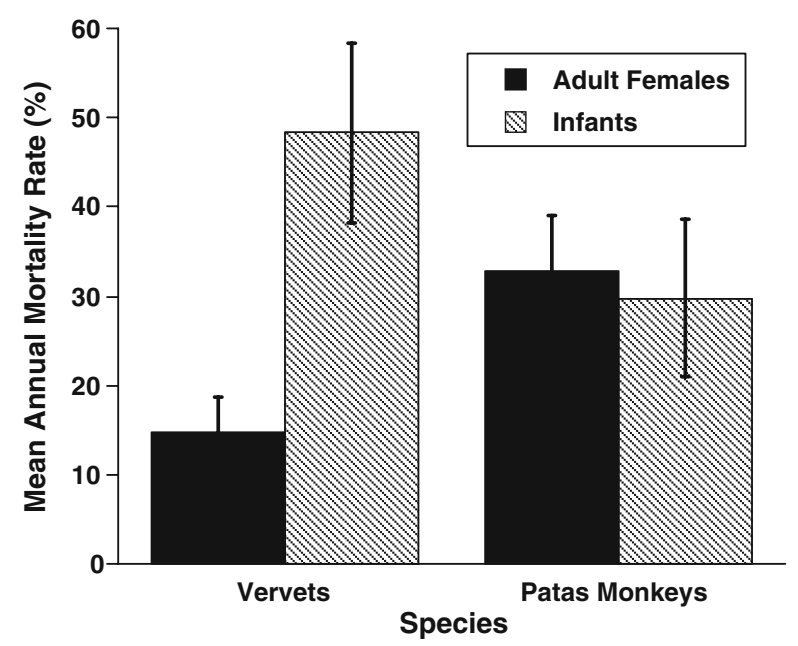

Fig. 4 Mean annual mortality rates of infant and adult female vervets and infant and adult female patas monkeys. Mortality patterns of vervets follow the mammalian norm of high infant mortality and lower adult female mortality. Patas monkeys are unusual in having relatively high adult female mortality vs. vervets and other primates.

mean annual mortality rate of infant patas was $29.8 \%( \pm 8.8)$ and that of adult female patas, 32.9\% ( \pm 6.1$)$. For the $5 \mathrm{yr}$ from 1994 until 1999, when the patas population was increasing, annual infant mortality was substantially lower $(15.4 \%$, range $=8$ $23 \%)$ than adult female mortality $(28.1 \%$, range $=19-47 \%)$. Adult female mortality during this period of population increase was similar to the mean annual adult female mortality of $26 \%$ in a population of Erythrocebus patas patas in Cameroon (Nakagawa et al. 2003). In those $5 \mathrm{yr}, 2.0$ infants died each year on average (range= $1-3$, median $=2$ ), whereas 4.0 adult females died each year on average (range $=3-8$, median=3; Table I). Indeed, the average infant patas monkey was more likely to be alive a year after its birth than its own mother during those $5 \mathrm{yr}$. The later years of population decline were noticeably different, with mortality increasing for both infants and adult females, but more so for infants. Mean annual infant mortality increased to $47.9 \%$, and mean annual adult female mortality, $47.0 \%$. Throughout the study, a mean of 2.4 infants (range $=05 ; n=9 \mathrm{yr}$ ) and 3.7 adult females died each year (range $=0-7, n=10$ years; Table I).

Of the 11 adult female patas monkeys that were parous in 1993, and so were $\geq 3 \mathrm{yr}$ of age, the average age at death was minimally $6.2 \pm 0.4 \mathrm{yr}$ (range $=5-9 \mathrm{yr}$ ). All parous females died before the study ended. The oldest adult female patas monkey was $\geq 9$ yr old when she died. Based on her appearance, it is unlikely that she could have been as old as the maximum age of $17 \mathrm{yr}$ in Erythrocebus patas patas in Cameroon (Nakagawa et al. 2003). Of the 24 female patas monkeys that were born during the study and survived long enough to become adult, 22 died before the end of the study. The average age at death for those females was $4.7 \pm 0.3 \mathrm{yr}$ (range $=3$ 7 yr). Only 2 of 39 adult female patas were still alive in the group by the end of the study; 1 was 6 and the other was 7 yr old. 
In vervets, annual infant mortality was significantly higher than annual adult female mortality (Mann-Whitney $U$ test, $U=9.5, z=2.81, n_{1}=8, n_{2}=11, p=0.005$; Fig. 4). In patas monkeys, annual infant mortality was not significantly different from annual adult female mortality $\left(U=53.5, z=-0.65, n_{1}=9, n_{2}=10, p=0.52\right.$; Fig. 4). Adult female mortality was significantly higher in patas monkeys than in vervet monkeys $\left(U=23, z=2.22, n_{1}=10, n_{2}=11, p=0.03\right)$. Infant mortality was not significantly different between the 2 species $\left(U=52, z=-1.49, n_{1}=9, n_{2}=8, p=0.14\right.$; Fig. 4). In vervets, yearly juvenile mortality ranged from 0 to $36 \%$ across $8 \mathrm{yr}$ (with 1 outlier of $77 \%)$. Mean annual juvenile vervet mortality was $18.9 \% \pm 9.2(10.7 \%$ excluding the outlier). In patas monkeys, estimated yearly juvenile mortality ranged from $13 \%$ to $50 \%$ across 8 yr (with 1 outlier of $75 \%$ ). Estimated mean annual mortality of juvenile patas monkeys was $32.5 \% \pm 7.3$ (26.4\% excluding the outlier). Juvenile mortality rates did not differ significantly between species $\left(U=14, z=1.84, n_{1}=8, n_{2}=8, p=0.07\right)$ despite our undoubtedly inflated mortality rate of juvenile patas monkeys. We counted all disappearances of juvenile patas monkeys as dying, but males (those that we did not identify as individuals) could have dispersed instead. Male patas monkeys typically disperse around 2.5-3 yr of age (Rogers and Chism in press).

\section{Extrinsic Causes of Mortality in Vervets}

Suspected or confirmed predation accounted for the deaths of $\geq 7$ of $15(47 \%)$ adult female vervets based on our definitions of confirmed and suspected predation. One year, 1999, accounted for 5 deaths from confirmed or suspected predation. In that year, at least 2 vervet groups along the river, including 1 of the 2 intensively studied groups, were decimated over a 6-mo period. During $1 \mathrm{wk}$ alone, 11 of $21(52 \%)$ individuals in 1 of the main study groups died. We observed a female leopard and 2 large cubs, and their tracks, in the area shortly before and during that time, and found remains of some of the subjects along with leopard tracks, strongly implicating leopards as the predators. After that week, we did not see the other main focal group for a month. When we next observed it, in August 1999, it was missing an individual and had fused with the decimated group. Six months later, we found the remains of 3 vervets scattered in and around the tree in which the group had slept the previous night, with claw marks on the trunk of the tree. Leopard predation stopped abruptly after that and no non-infants disappeared during the following 2 yr. Predation is also implicated in the death of 1 more adult female because the simultaneous deaths of apparently healthy infants and mothers are difficult to explain any way other than predation. One mother-infant pair disappeared together, suggesting that $\geq 8$ adult female vervets (53\%) died of predation (Fig. 5).

Among infant vervets, including the infant that died with its mother, $\geq 9$ of 28 (32.1\%) died of confirmed and suspected predation. Two (8.0\%) infant vervets, both $<6$ mo of age, died shortly after their mothers died, 1 of apparent dehydration (Enstam et al. 2002). We confirmed the finding from Amboseli that infant vervets $>12$ mo can survive the loss of their mothers (Lee 1983); in fact 1 vervet at our study site was orphaned at 6 mo and survived its first year. Other females took no infant 


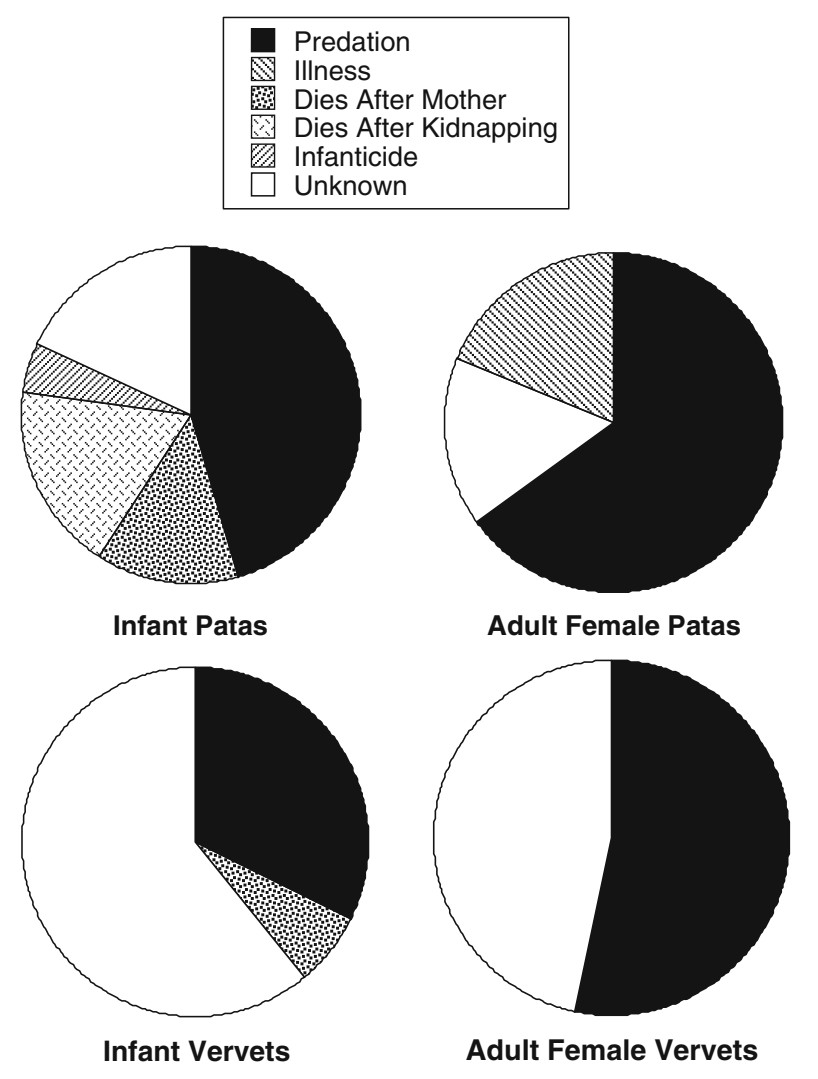

Fig. 5 Probable causes of mortality in infant and adult female patas monkeys and vervets.

vervets from their mothers or mistreated them. No infants or adult female vervets disappeared while showing signs of illness (Fig. 5).

The Association Between Rainfall and Mortality in Infant Vervets

Based on our 3-d window of time for assigning probable causes to deaths, we could not determine the cause of death for 17 infant vervets $(60.1 \%)$ and $4(18.2 \%)$ infant patas monkeys. To obtain a better understanding of the risks to infants, we consulted the literature to consider other possible causes of infant mortality. Infectious diseases, in general, and respiratory diseases, in particular, are a major cause of mortality in human infants (Cartwright 2002; Greenwood 1999), and the incidence of respiratory diseases can increase during cold or wet months (Dowell et al. 2003; Sugaya and Takeuchi 2005; Talbot et al. 2005). Deaths after respiratory diseases also occur in nonhuman primates [mountain gorillas (Gorilla gorilla berengei) and gelada baboons (Theropithecus gelada)], and they follow the human pattern of increasing in frequency during wetter or colder weather (Dunbar 1980; Watts 1998). We therefore asked whether or not an association exists between rainfall and infant mortality in vervets. We compared rainfall in the birth month for all infant vervets 
that we classified as dying of unknown causes and all infants that survived their first year $(n=24)$. Infant vervets that died of unknown causes were born in months with significantly higher rainfall than survivors $(U=107.5, z=2.54, p<0.01$; Fig. 6), suggesting that climatic conditions may indeed affect infant survivorship.

\section{Extrinsic Causes of Mortality in Patas Monkeys}

Confirmed and suspected predation accounted for the deaths of $\geq 17$ of 37 (45.9\%) adult female patas monkeys. There are several indications that this value is substantially underestimated, and underestimated more than for vervets. First, it was more difficult to find remains of patas monkeys than those of vervets, partly because patas monkeys have very large home ranges (Chism and Rowell 1988). We found remains of adult female patas monkeys only once; there was no evidence of predation on this individual. Their large home ranges also made it more difficult to find them within our 3-d window for classifying disappearances as suspected predation. Finally, more mother and infant patas monkeys ( 7 pairs) died together than mother and infant vervets (1 pair). It is difficult to suspect anything but predation when mothers and infants disappear together. Including the deaths of these 7 adult female patas monkeys as suspected predation suggests that $\geq 24$ of 37 (64.9\%) adult female patas monkeys died of suspected or confirmed predation (Fig. 5).

Six $(16.2 \%)$ adult female patas monkeys developed a largely fatal illness, 5 of them shortly after the El Niño rains of 1997-1998 (Fig. 5). The 5 that became ill after the heavy rains represented $35 \%$ of the adult female population at that time. The most obvious symptom included weakening and stiffening of the hind limbs, which caused the afflicted individuals to stumble and walk slowly, move sideways as they walked forward, and collapse after jumping down from trees. Other symptoms included

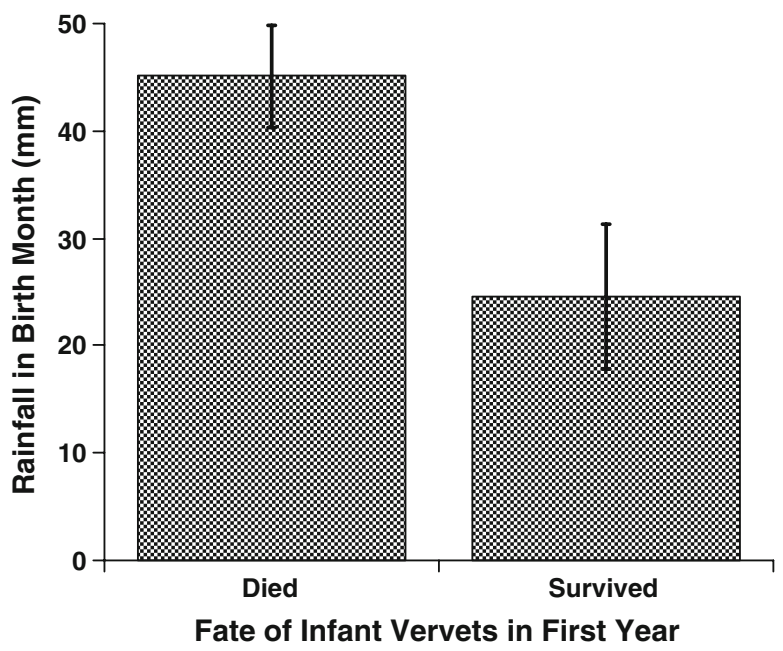

Fig. 6 Association between survival of infant vervets and rainfall in the birth month. Infants that did not survive their first year were born in significantly wetter months than infants that did survive their first year. 
visible weight loss, lethargy, and apparent confusion, and in some individuals, corneal opacity in 1 eye or tremors of the head. Afflicted individuals rested frequently, often lying on their sides on the ground rather than sitting, the typical posture of terrestrially resting patas. The degeneration was largely irreversible. Only 1 of the 6 adult females improved. That female had a minor degree of hind limb weakness and stiffness compared to the others, and she survived $>2 \mathrm{yr}$ with apparent blindness in 1 eye. Although another female continued to keep up with the group for $>1$ yr before falling behind and disappearing, the other 4 died in $\leq 4$ mo. Reproduction also dropped precipitously from previous years; only $27 \%$ of all adult females gave birth in 1999 .

Among infant patas monkeys, $\geq 3$ of 22 (13.6\%) died of suspected predation. When we combined the 7 infants that died with their mothers with these 3 , an estimated $45.4 \%$ of infant patas monkeys had died of suspected predation. Three infant patas monkeys (13.6\%), all $<6$ mo of age, died shortly after their mothers died, whereas 1 orphaned 6-mo-old was able to survive even after it became separated from its group and traveled alone for $\geq 4 \mathrm{~d}$ to $\leq 12 \mathrm{~d}$. Four (18.2\%) infant patas monkeys died when they were kidnapped by adult females immediately after birth and handled roughly. We observed the behavior during only 1 birth season, and it followed the first year of very poor reproduction in which only $27 \%$ of all adult females reproduced. One $(4.5 \%)$ infant patas monkey died of suspected infanticide (Enstam et al. 2002; Fig. 5).

In summary, suspected and confirmed predation was the major source of mortality for both infants and adult females in both species. Illness, coinciding with the heavy rains of 1997-1998, was a secondary source of mortality for adult female patas monkeys but not adult female vervets. Infants in both species invariably died shortly after their mothers died if they were $<6$ mo of age; orphans 6 mo old were able to survive. Kidnapping and suspected infanticide contributed to the deaths of infant patas monkeys but not infant vervets. Infant vervets whose deaths were not attributable to any known cause were more likely to die in their first year than those born in drier months and may have been more susceptible to infectious illnesses. We nonetheless still classified the cause of mortality as unknown for those 17 of 28 $(60.7 \%)$ infant vervets. We also could not determine the cause of mortality for 7 of $15(47 \%)$ adult female vervets, 7 of $37(18.9 \%)$ adult female patas monkeys, and 4 of $22(18.1 \%)$ infant patas monkeys (Fig. 5).

\section{Discussion}

The Extraordinary Life History of Patas Monkeys

For their body size, adult female patas monkeys have the highest intrinsic population growth rate of any haplorhine primate (Fig. 1). In primates, as in most mammals, infant mortality is typically much greater than adult female mortality (Cheney et al. 2004; Dobson and Lyles 1989; Pochron et al. 2004; Wich et al. 2007). Patas monkeys are an exception. The high mortality rate of adult female patas monkeys is similar to that reported for mouse lemurs (Microcebus spp.), even though there is a 40-fold difference in body size (Lutermann et al. 2006; Rowe 1996). High mortality of adult female patas monkeys relative to that of adult female vervets supports 
predictions of the demographic model of life history evolution that argues that ageclass specific relative mortality drives evolutionary differences in intrinsic population growth rate via high reproductive rate and early age at first reproduction. In contrast, interpecific differences in infant and juvenile mortality were minimal. Although both species had high immature mortality rates, the mortality rate of immature patas monkeys was, unusually, not significantly different from that of adult female patas monkeys. Our results are consistent with other research suggesting that adult mortality is likely to drive life history evolution (Reznick and Bryant 2007; Reznick et al. 2001; Young 1981, 1990). In particular, higher adult mortality, relative to immatures, is predicted to favor the evolution of genotypes with fast lives, i.e., with short lifespans, early age at maturity, and rapid reproductive output, whereas lower adult mortality is predicted to favor the evolution of genotypes with slow lives, i.e., with longer lifespans, later maturity, and slower reproductive output (Charnov 1993; Franco and Silvertown 1996; Stearns 1992; Young 1981). The uniquely high maximum potential rates of increase in patas monkeys relative to vervets, and indeed, relative to all other haplorhine primates, can thus be explained as an evolutionary response to their unusual degree of high adult female mortality relative to infant mortality.

One of the most consistent results from the analysis of primate life history patterns has been the strong negative relationship between body size and intrinsic rate of population growth (Ross, 1992), which researchers have sometimes interpreted in the context of $r$ - and K-selection. Patas monkeys represent an outlier to this relationship. Another major outlier is the ruffed lemur (Varecia variegata; Ross 1992). It would be interesting to examine whether that species also exhibits particularly high adult mortality.

Some models of life history evolution argue that fluctuating population sizes or unpredictable environments favor r-selected life history traits (Resnick et al. 2002). In another approach to primate life histories, researchers invoked differences in climatic predictability to explain life histories of several lemur species, although without specifics concerning age-class specific mortality patterns (Dewar and Richard 2007; Richard et al. 2002; Wright 1995). Unpredictable environments may produce populations that are often rapidly growing, and rapidly growing populations may in fact have low immature mortality, but even in stable, nonincreasing populations, lower immature and higher adult mortality should result in the evolution of early and frequent reproduction among individuals in those populations. In many fluctuating populations, there are periods of rapid population growth characterized by relatively high juvenile survivorship. This is supported by the finding that numbers of patas monkeys fluctuated more than numbers of vervets. However, we argue that the stronger selective force favoring early and frequent reproduction in patas monkeys is their higher than normal, for mammals, adult mortality compared to their infant mortality because the pattern was consistent across their population fluctuations, and was not restricted to the early period of population growth. Populations of patas monkeys may fluctuate more than those of other species, but more importantly, their demography is characterized by consistently low adult survival relative to immature survival, and this has apparently favored their extraordinarily early and frequent reproduction.

Indeed, the demography and life history of patas monkeys may make them more susceptible to population fluctuations. In a species that relies so heavily on 
recruitment, even a few years of recruitment failure (in this case, both lowered birth rates in 1999 and higher infant mortality in 1999-2001) can have profound effects on population size. Even during the period of patas population growth, population size declined appreciably between birth seasons each year (Fig. 3). The rate of decline during 1999 was similar, but was not compensated by good recruitment in later years.

It is also possible that there is an evolutionary feedback in r-selected species that further increases adult female mortality. If underlying mortality schedules favor early reproductive effort, early reproduction may be associated with its own increased mortality costs via limits to resource allocation (Descamps et al. 2006). Harvey et al. (1989) attributed the short lifespans of species with high reproductive rates in general to such an evolutionary trade-off. However, the high adult mortality of patas monkeys here was not due to intrinsic causes, but to extrinsic environmental hazards.

\section{Patterns of Mortality in Patas Monkeys and Vervets}

High vulnerability to environmental hazards may ultimately be responsible for low adult survival, and may include predation and intraspecific competition for food (Austad and Fischer 1992; Reznick et al. 2002). Adult female patas monkeys had lower survivorship than adult female vervets throughout the study. Although one could attribute much of the mortality of both species to predation, patas monkeys may face relatively greater risk of predation than vervets. The vegetation at our study site is primarily Acacia drepanolobium bushed grassland (Young et al. 1997, 1998), with ribbons of $A$. xanthophloea woodland along wet drainages. Patas monkeys spent all, and vervets most, of their time in Acacia drepanolobium bushed grassland. Vervets also often fed and always slept in Acacia xanthophloea, but patas monkeys rarely used these trees (Enstam and Isbell 2004). At our study site, Acacia drepanolobium, the tree species most quickly accessible to patas monkeys, averages only $2.6 \mathrm{~m}$ in height and tree canopies rarely touch (Enstam and Isbell 2002). During the day, the trees afford some advantage in detecting predators (Enstam and Isbell 2004) but little protection if the predator acts. Patas monkeys employ trees to help them detect predators but avoid potential predators more by running away than by climbing trees, an unusual response for primates (Enstam and Isbell 2002). Patas monkeys also have other unusual adaptations that Chism and Rowell (1988) and Chism et al. (1983) have attributed to high predation, including diurnal births, infrequent use of the same trees for sleeping, limited co-sleeping of group members within the same tree, and specialized morphology for cursoriality.

Although predation is also a major cause of mortality for vervets, access to groves of very tall trees with interconnected canopies may help to reduce predation during the day, if not as much during the night (Enstam and Isbell 2002). The intense episodic predation experienced by the vervets in Laikipia is similar to that reported for vervets in Amboseli (Isbell 1990) and corroborates the pattern seen in Amboseli that episodic bursts of mortality can occur as a result of predation by leopards (Isbell 1994).

Illness is an additional hazard. It was epidemic in adult patas monkeys and perhaps chronic in infant vervets. What might have caused the epidemic? One possibility that deserves further investigation is plant toxicity. Many plant toxins cause diseases of the central nervous system. Fungal infestations of plants, in particular, are facilitated by wet conditions, and some are known to affect motor 
control of those ingesting the plants (Cheeke 1989a, b). For example, a fungus that attacks the seedheads of Cynodon dactylon (Kellerman et al. 1988), a common grass at our study site, causes sheep and cattle that ingest it to acquire many of the same symptoms (Kellerman et al. 1988) that we observed in patas monkeys. It is interesting that we observed no infant patas monkeys with the illness, which argues against the epidemic illness being an infectious disease.

In contrast, infectious diseases may be an important factor in the lives of vervets. For example, the vervets' preference for living along rivers or other wet areas within otherwise dry habitats may make them more susceptible to respiratory illnesses, because the microclimate near rivers and swamps can be damper for a given amount of rainfall. At Segera, localized fogs occurred only along the river where the vervets slept and were especially frequent during the main birth season months of JanuaryMarch, when the less developed immune systems of infants are likely to be more vulnerable to pathogens. Unfortunately, respiratory diseases are difficult to detect noninvasively in wild animals. Even in humans, the causal agent of respiratory illness is difficult to determine via behavioral signs alone. For example, bacterial pneumonia is accurately diagnosed behaviorally only by measuring respiratory rate and chest indrawing (Harari et al. 1991; Shann 1995), neither of which is possible to measure in wild primates without capturing them.

While patas monkeys experience similar amounts of rain as vervets at our study site, they typically avoid rivers (Isbell in press) and are less exposed to damp conditions. Indeed, they may suffer from wet weather only under extraordinary circumstances, such as occurred after the El Niño rains of 1997-1998. They are also able to withstand the frequent droughts that occur in this region and thrive when other animals suffer from lack of food (Isbell and Chism 2007). This suggests that intraspecific competition for food is not an environmental hazard affecting survivorship in patas monkeys and it is consistent with observations that behavioral competition for food is relatively less important in patas monkeys than in vervets (Isbell 1998; Isbell and Pruetz 1998; Isbell et al. 1998; Pruetz and Isbell 2000). Indeed, heavy predation may even reduce competition in the short term by making food more available for survivors (Isbell 1994; Reznick et al. 2002). In contrast, food limitation may increase susceptibility to infectious diseases (Ullrey 1993), perhaps one contributor to the apparent difference between patas monkeys and vervets in chronic illness. Regardless of the multiple potential selective pressures that may affect mortality and the complexity of their interactions, the lives of patas monkeys and vervets suggest that ultimately, life history evolution pays attention to age-specific mortality patterns.

Our study provides the first quantitative evidence from closely related sympatric mammals to support the demographic model of life history evolution. Populations of patas monkeys may fluctuate more than those of other species, but more importantly, their demography is characterized by consistently low adult survival relative to immature survival, which has apparently favored their extraordinarily early and frequent reproduction.

Acknowledgments We thank Christopher Motokaa, Julius, Sumat, N. Moinde, S. Williams, M. Nyokabi, R. Mohammed, F. Ram Ram, G. Kimathi, R. Carlson, J. Pruetz, C. Molel, J. Selengat, D. Eckdahl, S. and V. Cummins, and especially A. Nderitu and B. Musyoka Nzuma for field assistance; G. Small, J. Wreford-Smith, G. Prettijohn, T. Butynski, and J. Kalina for logistical support, and R. Fonville, J. 
Ruggieri, and J. Gleason Skow for permission to conduct the study on their property. We also thank the Kenya National Museums (M. Isahakia) and the Institute of Primate Research (M. Bambra and J. Mwenda) for local sponsorship. Grants from the National Science Foundation, Leakey Foundation, Wenner-Gren Foundation for Anthropological Research, National Geographic Society, BBC, Discovery Canada, ZDF, Fulbright (IIE), Animal Behavior Society, Sigma Delta Epsilon-Graduate Women in Science (Ruth Dickie Scholarship), the University of Wisconsin, Rutgers University, and the University of California supported this research. This research was approved under prevailing institutional rules governing research with animals. Two anonymous reviewers offered constructive suggestions for improving the manuscript, and T. Kornak nicely copyedited the accepted manuscript. We greatly appreciate their efforts.

Open Access This article is distributed under the terms of the Creative Commons Attribution Noncommercial License which permits any noncommercial use, distribution, and reproduction in any medium, provided the original author(s) and source are credited.

\section{References}

Austad, S. N., \& Fischer, K. E. (1992). Primate longevity: Its place in the mammalian scheme. American Journal of Primatology, 28, 251-261. doi:10.1002/ajp.1350280403.

Bielby, J., Mace, G. M., Bininda-Emonds, O. R. P., Cardillo, M., Gittleman, J. L., Jones, K. E., Orme, C. D. L., \& Purvis, A. (2007). The fast-slow continuum in mammalian life history: An empirical reevaluation. American Naturalist, 169, 748-757. doi:10.1086/516847.

Cartwright, K. (2002). Pneumococcal disease in western Europe: Burden of disease, antibiotic resistance and management. European Journal of Pediatrics, 161, 188-195. doi:10.1007/s00431-001-0907-3.

Caughley, G. (1966). Mortality patterns in mammals. Ecology, 47, 906-918. doi:10.2307/1935638.

Caughley, G. (1977). Analysis of Vertebrate Populations. New York: John Wiley.

Charnov, E. L. (1993). Life History Invariants: Some Explorations of Symmetry in Evolutionary Ecology. Oxford: Oxford University Press.

Charnov, E. L., \& Shaffer, W. M. (1973). Life-history consequences of natural selection: Cole's result revisited. American Naturalist, 107, 791-793. doi:10.1086/282877.

Cheeke, P. R. (1989a). Toxicants of Plant Origin, Vol. 1: Alkaloids. Boca Raton, FL: CRC Press.

Cheeke, P. R. (1989b). Toxicants of Plant Origin, Vol. 2: Glycosides. Boca Raton, FL: CRC Press.

Cheney, D. L., Seyfarth, R. M., Andelman, S. J., \& Lee, P. C. (1988). Reproductive success in vervet monkeys. In T. H. Clutton-Brock (Ed.), Reproductive success: studies of individual variation in contrasting breeding systems (pp. 384-402). Chicago: University of Chicago Press.

Cheney, D. L., Seyfarth, R. M., Fischer, J., Beehner, J., Bergman, T., Johnson, S. E., Kitchen, D. M., Palombit, R. A., Rendall, D., \& Silk, J. B. (2004). Factors affecting reproduction and mortality among baboons of the Okavango Delta, Botswana. International Journal of Primatology, 25, 401-428. doi:10.1023/B:IJOP.0000019159.75573.13.

Chism, J., Olson, D., \& Rowell, T. (1983). Diurnal births and perinatal behavior among wild patas monkeys: Evidence of an adaptive pattern. International Journal of Primatology, 4, 167-184.

Chism, J., \& Rowell, T. (1988). The natural history of patas monkeys. In A. Gautier-Hion, F. Bourliere, J.P. Gautier, and Kingdon (eds.), A primate radiation: evolutionary biology of the african guenons (pp. 412-438). New York: Cambridge University Press.

Chism, J., Rowell, T., \& Olson, D. (1984). Life history patterns of female patas monkeys. In M. F. Small (Ed.), Female primates: studies by women primatologists (pp. 175-190). New York: Alan R. Liss.

Cole, L. (1954). The population consequences of life-history phenomena. The Quarterly Review of Biology, 29, 103-137. doi:10.1086/400074.

Descamps, S., Boutin, S., Berteaux, D., \& Gaillard, J.-P. (2006). Best squirrels trade a long life for an early reproduction. Proceedings of the Royal Society of London. Series B. Biological Sciences, 273, 23692374. doi:10.1098/rspb.2006.3588.

Dewar, R. E., \& Richard, A. F. (2007). Evolution in the hypervariable environment of Madagascar. Proceedings of the National Academy of Sciences of the United States of America, 104, 13723-13727. doi:10.1073/pnas.0704346104.

Dobson, A. P., \& Lyles, A. M. (1989). The population dynamics and conservation of primate populations. Conservation Biology, 3, 362-380. doi:10.1111/j.1523-1739.1989.tb00242.x.

Dowell, S. F., Whitney, C. G., Wright, C., Rose Jr, C. E., \& Schuchat, A. (2003). Seasonal patterns of invasive pneumococcal disease. Emerging Infectious Diseases, 9, 573-579. 
Dunbar, R. I. M. (1980). Demographic and life history variables of a population of gelada baboons (Theropithecus gelada). Journal of Animal Ecology, 49, 485-506. doi:10.2307/4259.

Enstam, K. L., \& Isbell, L. A. (2002). Comparisons of responses to alarm calls by patas (Eythrocebus patas) and vervet (Cercopithecus aethiops) monkeys in relation to habitat structure. American Journal of Physical Anthropology, 119, 3-14. doi:10.1002/ajpa.10104.

Enstam, K. L., \& Isbell, L. A. (2004). Microhabitat preferences and vertical use of space by patas monkeys (Erythrocebus patas) in relation to predation risk and habitat structure. Folia Primatologica, 75, 70-84. doi:10.1159/000076265.

Enstam, K. L., Isbell, L. A., \& DeMaar, T. (2002). Male demography, female mating behavior, and infanticide in wild patas monkeys, Erythrocebus patas. International Journal of Primatology, 23, 85104. doi:10.1023/A:1013249808137.

Franco, M., \& Silvertown, J. (1996). Life history variation in plants: An exploration of the fast-slow continuum hypothesis. Philosophical Transactions of the Royal Society of London. Series B, Biological Sciences, 351, 1341-1348. doi:10.1098/rstb.1996.0117.

Greenwood, B. (1999). The epidemiology of pneumococcal infection in children in the developing world. Philosophical Transactions of the Royal Society of London. Series B, Biological Sciences, 354, 777785. doi:10.1098/rstb.1999.0430.

Harari, M., Shann, F., Spooner, V., Meisner, S., Carney, M., \& de Campo, J. (1991). Clinical signs of pneumonia in children. Lancet, 338, 928-930. doi:10.1016/0140-6736(91)91785-S.

Harvey, P. H., \& Clutton-Brock, T. H. (1985). Life history variation in primates. Evolution; International Journal of Organic Evolution, 39, 559-581. doi:10.2307/2408653.

Harvey, P. H., Promislow, D. E. L., \& Read, A. F. (1989). Causes and correlates of life history differences among mammals. In V. Standen, \& R. A. Foley (Eds.), Comparative socioecology: the behavioural ecology of humans and other mammals (pp. 305-318). Oxford: Blackwell Scientific Publications.

Isbell, L. A. (1990). Sudden short-term increase in mortality of vervet monkeys (Cercopithecus aethiops) due to leopard predation in Amboseli National Park, Kenya. American Journal of Primatology, 21, 41-52. doi:10.1002/ajp.1350210105.

Isbell, L. A. (1994). Predation on primates: Ecological patterns and evolutionary consequences. Evolutionary Anthropology, 3, 61-71. doi:10.1002/evan.1360030207.

Isbell, L. A. (1998). Diet for a small primate: Insectivory and gummivory in the (large) patas monkey (Erythrocebus patas pyrrhonotus). American Journal of Primatology, 45, 381-398. doi:10.1002/ (SICI)1098-2345(1998)45:4<381::AID-AJP5>3.0.CO;2-S.

Isbell, L. A. (in press). Erythrocebus patas. In T. M. Butynski, J. S. Kingdon, \& Kalina, J. (Eds.), The mammals of Africa, vol. 2: Primates. Amsterdam: Academic Press.

Isbell, L. A., \& Chism, J. (2007). Distribution and abundance of patas monkeys (Erythrocebus patas) in Laikipia, Kenya, 1979-2004. American Journal of Primatology, 69, 1223-1235. doi:10.1002/ ajp. 20427.

Isbell, L. A., \& Enstam, K. L. (2002). Predator (in)sensitive foraging in sympatric female vervets (Chlorocebus aethiops) and patas monkeys (Erythrocebus patas): A test of ecological models of group dispersion. In L. E. Miller (Ed.), Eat or be eaten: Predator sensitive foraging in nonhuman primates (pp. 154-168). New York: Cambridge University Press.

Isbell, L. A., \& Jaffe, K. E. (in press). Cercopithecus pygerythrus. In T. M. Butynski, J. S. Kingdon, \& J. Kalina (Eds.), The mammals of Africa, vol. 2: Primates. Amsterdam: Academic Press.

Isbell, L. A., \& Pruetz, J. D. (1998). Differences between vervets (Cercopithecus aethiops) and patas monkeys (Erythrocebus patas) in agonistic interactions between adult females. International Journal of Primatology, 19, 837-855. doi:10.1023/A:1020393329574.

Isbell, L. A., Pruetz, J. D., \& Young, T. P. (1998). Movements of vervets (Cercopithecus aethiops) and patas monkeys (Erythrocebus patas) as estimators of food resource size, density, and distribution. Behavioral Ecology and Sociobiology, 42, 123-133. doi:10.1007/s002650050420.

Kellerman, T. S., Coetzer, J. A. W., \& Naudé, T. W. (1988). Plant poisonings and Mycotoxicoses of livestock in Southern Africa. Cape Town, South Africa: Oxford University Press.

Lee, P. C. (1983). Effects of the loss of the mother on social development. In R. A. Hinde (Ed.), Primate social relationships: An integrated approach (pp. 73-79). Oxford: Blackwell Scientific Publications.

Loy, J. (1974). Changes in facial color associated with pregnancy in patas monkeys. Folia Primatologica, 22, 251-257. doi:10.1159/000155630.

Lutermann, H., Schmelting, B., Radespiel, U., Ehresmann, P., \& Zimmerman, E. (2006). The role of survival for the evolution of female philopatry in a solitary forager, the grey mouse lemur (Microcebus murinus). Proceedings of the Royal Society of London. Series B. Biological Sciences, 273, 25272533. doi:10.1098/rspb.2006.3603. 
MacArthur, R. H., \& Wilson, E. O. (1967). The theory of island biogeography. Princeton, NJ: Princeton University Press.

McNaughton, S. J. (1985). Ecology of a grazing ecosystem: The Serengeti. Biology Monographs, 55, 259-294. doi:10.2307/1942578.

Nakagawa, N., Ohsawa, H., \& Muroyama, Y. (2003). Life history parameters of a wild group of West African patas monkeys (Erythrocebus patas patas). Primates, 44, 281-290. doi:10.1007/s10329-0030042-z.

Orzack, S., \& Tuljapurkar, S. (1989). Population dynamics in variable environments. VII. Demography and evolution of iteroparity. American Naturalist, 133, 901-923. doi:10.1086/284959.

Orzack, S. H., \& Tuljapurkar, S. (2001). Reproductive effort in variable environments, or environmental variation is for the birds. Ecology, 82, 2659-2665. doi:10.2307/2679944.

Pianka, E. R. (1970). On r- and K-selection. American Naturalist, 104, 592-597. doi:10.1086/282697.

Pochron, S. T., Tucker, W. T., \& Wright, P. C. (2004). Demography, life history, and social structure in Propithecus diadema edwardsi from 1986-2000 in Ranomafana National Park, Madagascar. American Journal of Physical Anthropology, 125, 61-72. doi:10.1002/ajpa.10266.

Pruetz, J. D., \& Isbell, L. A. (2000). Correlations of food distribution and patch size with agonistic interactions in female vervets (Chlorocebus aethiops) and patas monkeys (Erythrocebus patas) living in simple habitats. Behavioral Ecology and Sociobiology, 49, 38-47. doi:10.1007/s002650000272.

Reznick, D., \& Bryant, M. (2007). Comparative long-term mark-recapture studies of guppies (Poecilia reticulata): Differences among high and low predation localities in growth and survival. Annales Zoologici Fennici, 44, 152-160.

Reznick, D., Butler, M. J., \& Rodd, H. (2001). Life-history evolution in guppies. VII. The comparative ecology of high- and low-predation environments. American Naturalist, 157, 126-140. doi:10.1086/318627.

Reznick, D., Bryant, M. J., \& Bashey, F. (2002). r- and K-selection revisited: The role of population regulation in life-history evolution. Ecology, 83, 1509-1520.

Richard, A. (1985). Primates in nature. New York: W. H. Freeman.

Richard, A. F., Dewar, R. E., Schwartz, M., \& Ratsirarson, J. (2002). Life in the slow lane? Demography and life histories of male and female sifaka (Propithecus verreauxi verreauxi). Journal of Zoology, 256, 421-436.

Rogers, W., \& Chism, J. Male dispersal in patas monkeys (Erythrocebus patas). Behaviour, in press.

Ross, C. (1988). The intrinsic rate of natural increase and reproductive effort in primates. Journal of Zoology, 214, 199-219.

Ross, C. (1992). Environmental correlates of the intrinsic rate of natural increase in primates. Oecologia, 90, 383-390. doi:10.1007/BF00317695.

Rowe, N. (1996). The pictorial guide to the living primates. East Hampton, New York: Pogonias Press.

Shann, F. (1995). The management of pneumonia in children in developing countries. Clinical Infectious Diseases, 21(Supplement 3), S218-S225.

Stearns, S. C. (1992). The evolution of life histories. New York: Oxford University Press.

Sugaya, N., \& Takeuchi, Y. (2005). Mass vaccination of schoolchildren against influenza and its impact on the influenza-associated mortality rate among children in Japan. Clinical Infectious Diseases, 41, 939-947. doi:10.1086/432938.

Talbot, T. R., Poehling, K. A., Hartert, T. V., Arbogast, P. G., Halasa, N. B., Edwards, K. M., Schaffner, W., Craig, A. S., \& Griffin, M. R. (2005). Seasonality of invasive pneumococcal diseases: Temporal relation to documented influenza and respiratory syncytial viral circulation. The American Journal of Medicine, 118, 285-291. doi:10.1016/j.amjmed.2004.09.016.

Tosi, A. J., Detwiler, K. M., \& Disotell, T. R. (2005). X-chromosomal window into the evolutionary history of the guenons (Primates: Cercopithecini). Molecular Phylogenetics and Evolution, 36, 58-66. doi:10.1016/j.ympev.2005.01.009.

Tosi, A. J., Disotell, T. R., Morales, J. C., \& Melnick, D. J. (2003). Cercopithecine Y-chromosome data provide a test of competing morphological evolutionary hypotheses. Molecular Phylogenetics and Evolution, 27, 510-521. doi:10.1016/S1055-7903(03)00024-1.

Tosi, A. J., Melnick, D. J., \& Disotell, T. R. (2004). Sex chromosome phylogenetics indicate a single transition to terrestriality in the guenons (tribe Cercopithecini). Journal of Human Evolution, 46, 223237. doi:10.1016/j.jhevol.2003.11.006.

Tuljapurkar, S. (1982). Population dynamics in variable environments. III. Evolutionary dynamics of r-selection. Theoretical Population Biology, 21, 141-165. doi:10.1016/0040-5809(82)90010-7.

Tuljapurkar, S. (1990). Delayed reproduction and fitness in variable environments. Proceedings of the National Academy of Sciences of the United States of America, 87, 1139-1143. doi:10.1073/ pnas.87.3.1139. 
Ullrey, D. E. (1993). Nutrition and predisposition to infectious disease. Journal of Zoo and Wildlife Medicine, 24, 304-314.

Watts, D. (1998). Seasonality in the ecology and life histories of mountain gorillas (Gorilla gorilla berengei). International Journal of Primatology, 19, 929-948. doi:10.1023/A:1020366018187.

Weeks, J. R. (1996). Population: An introduction to concepts and issues (6th ed.). New York: Wadsworth.

Wich, S. A., Steenbeek, R., Sterck, E. H. M., Korstjens, A. H., Willems, E. P., \& van Schaik, C. P. (2007). Demography and life history of Thomas langurs (Presbytis thomasi). American Journal of Primatology, 69, 641-651. doi:10.1002/ajp.20386.

Wright, P. C. (1995). Demography and life history of free-ranging Propithecus diadema edwardsi in Ranomafana National Park, Madagascar. International Journal of Primatology, 16, 835-854. doi:10.1007/BF02735722.

Young, T. P. (1981). A general model of comparative fecundity for semelparous and iteroparous life histories. American Naturalist, 118, 27-36. doi:10.1086/283798.

Young, T. P. (1990). The evolution of semelparity in Mount Kenya lobelias. Evolutionary Ecology 4, 157171.

Young, T. P., Stubblefield, C., \& Isbell, L. A. (1997). Ants on swollen-thorn acacias: species coexistence in a simple system. Oecologia, 109, 98-107. doi:10.1007/s004420050063.

Young, T. P., Okello, B., Kinyua, D., \& Palmer, T. M. (1998). KLEE: A long-term multi-species herbivore exclusion experiment in Laikipia, Kenya. African Journal of Range and Forage Science, 14, 92-104. 